\title{
Кинетика сорбции ванилина сильноосновным макропористым анионообменником Marathon MSA
}

\author{
Шолохова А.Ю., Елисеева Т.В., Воронюк И.В., \\ Селеменев В.Ф., Лукин А.Н.
}

ФГБОУ ВО «Воронежский государственньй университет», Воронеж

Поступила в редакцию 31.01.2017 г.

\begin{abstract}
В работе установлено, что сорбция ванилина (4-гидрокси-3-метоксибензальдегида) макропористым сильноосновным анионообменником Marathon MSA в ОН-форме имеет полимолекулярный характер. Методом ИК-спектроскопии подтверждены структурные изменения в фазе анионообменника, сорбировавшего данный гидроксибензальдегид. Изучена кинетика его сорбции анионообменником в статических условиях. На основе анализа кинетических кривых, построенных в координатах уравнений Бойда-Адамсона, оценена лимитирующая стадия сорбции ванилина исследуемым анионообменником. Установлено влияние температуры на ход кинетических кривых.
\end{abstract}

Ключевые слова: макропористый анионообменник, ванилин, изотерма сорбции, кинетика поглощения, влияние температуры, лимитирующая стадия сорбции.

\section{The kinetics of vanillin sorption by strong basic macro porous anion-exchange resin Marathon MSA}

\author{
Sholokhova A.Yu., Eliseeva T.V., Voronyuk I.V., \\ Selemenev V.F., Lukin A.N. \\ Voronezh State University, Voronezh
}

In the synthesis of 4-hydroxy-3-methoxybenzaldehyde (vanillin) some side products are formed in the reaction media so an important task is the elaboration of the procedure for vanillin selective extraction from technological solutions. It is shown that anion-exchange resins are effective sorbents of hydroxybezaldehydes. The isotherm of vanillin sorption by macro porous high basic anion-exchange resin Marathon MSA (Dow Chemical) in OH-form has been obtained in this work using the procedure of variable concentrations. It is found that sorption has a multimolecular type which deals with a possibility of vanillin molecules to dissociate in the phase of anion-exchange resin in $\mathrm{OH}$-form and to form vanillate-ions taking part in the anionexchange reactions. The additional uptake of vanillin caused by physical sorption also takes place in the system aromatic aldehyde solution - sorbent. Some of the supposed interactions are confirmed by the method of IR-spectroscopy.

Based on the kinetic curves of hydroxybenzaldehyde sorption by Marathon MSA resin the equilibrium time in the studied systems is determined for different concentrations and temperatures $(298,308$ and $323 \pm 2 \mathrm{~K})$. It is revealed that sorption equilibrium is reached rather rapidly in comparison with weak basic resins. The limiting stage of vanillin uptake is estimated using the formal approach of Boyd-Adamson.

Keywords: macro porous anion-exchange resin, vanillin, sorption isotherm, uptake kinetics, the influence of temperature, limiting stage of sorption.

\section{Введение}

Ванилин является не только важным ароматизатором в пищевой промышленности, но и за счет наличия реакционноспособных функциональных групп обеспечи- 
вает возможность получения из него производных, обладающих биологической активностью, антисептическими и бактерицидными свойствами [1-2]. При синтезе данного гидроксибензальдегида в реакционной смеси образуются побочные продукты, поэтому важным этапом получения чистого вещества становится селективное извлечение ванилина из технологических растворов. Современные тенденции в процессах извлечения чистых веществ направлены на привлечение сорбционных методов. Поскольку ванилин является слабым электролитом, то для его выделения могут быть использованы как ионогенные, так и неионогенные сорбенты. Исследования по применению неионогенных полимерных сорбентов для извлечения ароматических альдегидов за счет физической адсорбции описаны в [3]. Авторами [4] показана возможность использования анионообменников как сорбентов ванилина. В работе [5] установлено, что сорбция ванилина высокоосновным гелевым анионообменником, содержащим функциональные группы четвертичного аммониевого основания, протекает существенно быстрее по сравнению с сорбентами, включающими низкоосновные аминогруппы, что делает высокоосновные сорбенты перспективным технологическим материалом. Целью данной работы является установление особенностей сорбции ванилина высокоосновным макропористым анионообменником в статических условиях.

\section{Эксперимент}

Для изучения поглощения ванилина (4-гидрокси-3-метоксибензальдегида) в качестве сорбента использован сильноосновный макропористый анионообменник Marathon MSA (Dow Chemical) в гидроксильной форме. Данный сорбент представляет собой полимер со стирол-дивинилбензольной матрицей с функциональными группами четвертичного аммониевого основания. Исследование кинетики сорбции ванилина проводили в статических условиях в термостатируемом шейкере со скоростью перемешивания 250 об/мин, используя метод ограниченного объема [6]. По данным экспериментов строились зависимости F-t, где $\mathrm{F}=\mathrm{Q}_{\mathrm{t}} / \mathrm{Q}_{\max }-$ степень завершенности процесса сорбции; $\mathrm{Q}_{t}$ - емкость сорбента в момент времени $\mathrm{t}$, ммоль/г; $\mathrm{Q}_{\max }$ - емкость сорбента в состоянии равновесия, ммоль/г; $\mathrm{t}-$ время, мин. Концентрацию ванилина определяли спектрофотометрически (спектрофотометр «СФ2000») при длине волны 278 нм. Изотерму сорбции ванилина получали методом переменных концентраций при температуре $298 \pm 2$ К [ 6].

ИК-спектры исследуемых образцов анионообменника в ОН-форме и форме, насыщенной ванилином, получали в режиме пропускания на приборе ИК-Фурье спектрометр Bruker VERTEX 70 в диапазоне волновых чисел 4000-500 см-1. Для спектральных исследований образцы сорбента растирали и прессовали в виде таблеток с бромидом калия.

\section{Обсуждение результатов}

Ванилин является слабым электролитом $\left(\mathrm{pK}_{\mathrm{a}}=7.40\right)$, поэтому при рассмотрении процесса его сорбционного извлечения с применением ионообменных материалов следует учитывать наличие в растворе протонированной и депротонированной формы. На рис. 1 показана диаграмма распределения двух форм ванилина в зависимости от $\mathrm{pH}$, из которой видно, что в щелочной среде данный гидроксибензальдегид присутствует в растворе в виде ванилат-иона. Таким образом, он может сорбироваться анионообменником в гидроксильной форме по механизму ионного обмена за счет превращения молекулярной формы в анионную.

Шолохова и др. / Сорбционные и хроматографические процессы. 2017. Т. 17. № 2 


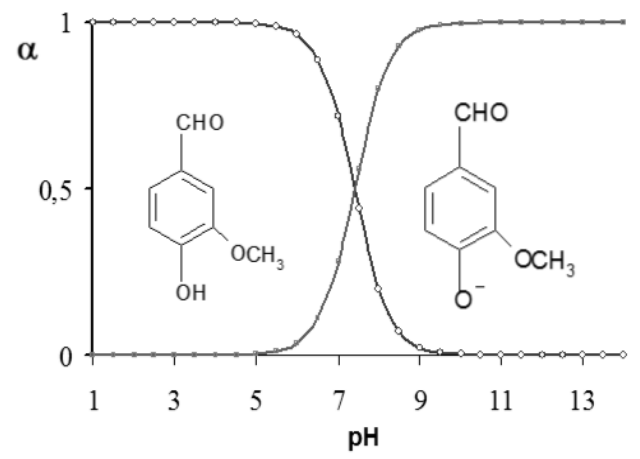

Рис. 1. Диаграмма распределения молекулярной и ионной форм ванилина в зависимости от рН среды.

В работе получена изотерма сорбции изучаемого гидроксибензальдегида сильноосновным анионообменником в ОН-форме, которая имеет полимолекулярный характер (рис. 2).

В фазе сорбента из-за высокого значения $\mathrm{pH}$ происходит диссоциация молекулы ванилина с образованием ванилат-иона, который может участвовать в реакции анионного обмена с функциональными группами сорбента. При концентрации раствора ванилина выше 5 ммоль/дм ${ }^{3}$ в системе раствор альдегида - сорбент возможны дополнительные взаимодействия помимо ионного обмена, о чем свидетельствует появление второй ступени на изотерме сорбции. Дополнительное поглощение ванилина может осуществляться за счет водородных связей, ван-дер-ваальсовых взаимодействий, по механизму стэкинг-эффекта.

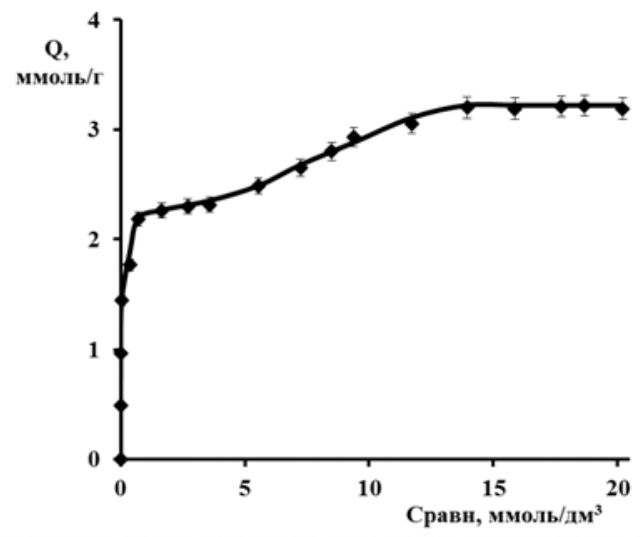

Рис. 2. Изотерма сорбции ванилина анионообменником Marathon MSA

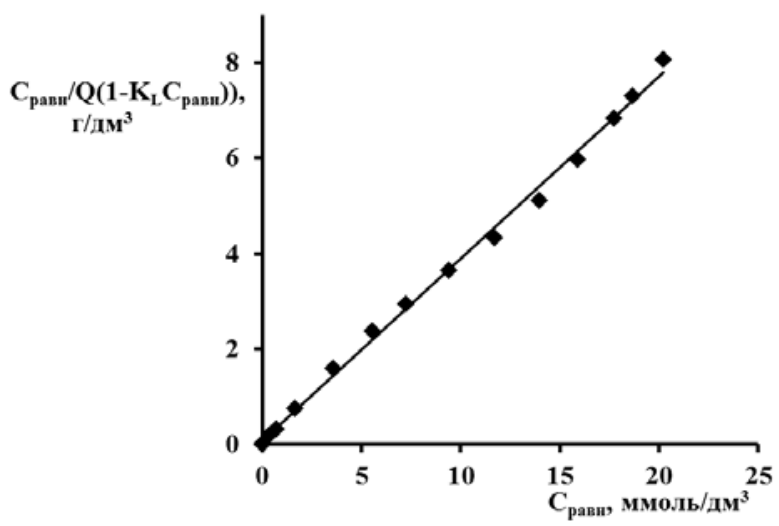

Рис. 3. Изотерма сорбции ванилина анионообменником Marathon MSA в координатах линейной формы уравнения БЭТ

Для описания изотермы сорбции гидроксибензальдегида во всем диапазоне исследованных концентраций было использовано уравнение полимолекулярной сорбции Брунауэра-Эммета-Теллера (БЭТ), модифицированное для жидких сред[9]:

$$
Q=Q_{\max } \frac{K_{s} C_{\text {pasн }}}{\left(1-K_{L} C_{p a s t}\right)\left(1-K_{L} C_{p a s t}+K_{s} C_{p a s H}\right)},
$$

где $\mathrm{K}_{\mathrm{s}}$ - константа сорбционного равновесия первого адсорбционного слоя, дм $^{3} /$ ммоль; $\mathrm{K}_{\mathrm{L}}$ - константа сорбционного равновесия для полимолекулярного слоя, дм $^{3} /$ ммоль. 
На рис. 3 представлена изотерма сорбции ванилина в координатах линейной формы уравнения БЭТ. Коэффициент корреляции полученной зависимости составил $\mathrm{R}^{2}=0.9973$, что подтверждает сложный полимолекулярный механизм поглощения ванилина.

При сравнении ИК-спектров поглощения анионообменника в ОН-форме и форме, сорбировавшей ванилин (рис. 4), выявлены изменения в структуре сорбента.

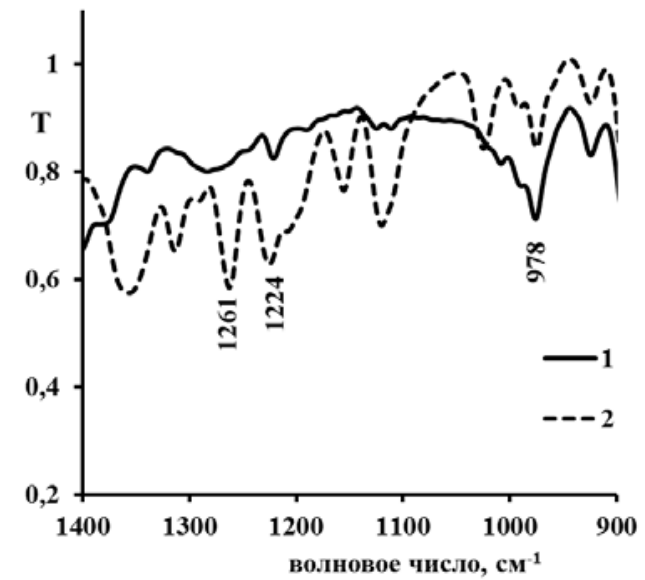

Рис. 4. ИК-спектр анионообменника Мarathon MSA: 1 - ОН-форма,

2 - форма, насыщенная ванилином

Наличие сорбированного ванилина в матрице анионообменника подтверждается пиками 1261, $1224 \mathrm{~cm}^{-1}$, характерными для эфирных групп в ароматических соединениях [10-11]. Несмотря на отсутствие анионов сорбата в растворе, участие функциональных групп сорбента в процессе поглощения гидроксибензальдегида по ионообменному механизму подтверждается уменьшением интенсивности полос поглощения в области $978 \mathrm{~cm}^{-1}$, характерных для деформационных колебаний $\mathrm{OH}^{-}-$ групп, связанных с четвертичным азотом $-\mathrm{N}^{+}\left(\mathrm{CH}_{3}\right)_{3} \cdots \mathrm{OH}^{-}[12]$.

Основной задачей работы являлось изучение кинетических характеристик сорбции ванилина сильносновным макропористым анионообменником. Получены кинетические кривые сорбции ванилина исследуемым анионообменником при концентрации исходного раствора гидроксибензальдегида 1.7 и 6.0 ммоль/дм ${ }^{3}$ (рис. 5) и исходных значениях рН растворов от 4.3 до 5.5, при которых ванилин находится исключительно в молекулярной форме. Установлено, что при концентрации ванилина 6.0 ммоль/дм ${ }^{3}$ время достижения равновесия составляет 60 мин, при концентрации 1.7 ммоль/дм ${ }^{3}-135$ мин.

На рис. 6 представлены кинетические кривые сорбции ванилина при температурах 298, 308 и $323 \pm 2 К$ для исходной концентрации раствора 6.0 ммоль/ дм³. Угол наклона кинетических кривых на начальных участках поглощения гидроксибензальдегида увеличивается при более высокой температуре, при этом время достижения равновесия уменьшается. При 323 К равновесие сорбционного процесса достигается за 40 минут. С ростом температуры сорбционная способность к исследуемому гидроксибензальдегиду снижается, при изменении температуры от 298 до 323К полная емкость анионообменника по ванилину уменьшается от 1.75 до 1.60 ммоль/г.

Для определения лимитирующей стадии исследуемого процесса полученные кинетические кривые сорбции представляли в координатах уравнения БойдаАдамсона для случая внешней диффузии (рис. 7) [13].

Шолохова и др. / Сорбционные и хроматографические процессы. 2017. Т. 17. № 2 


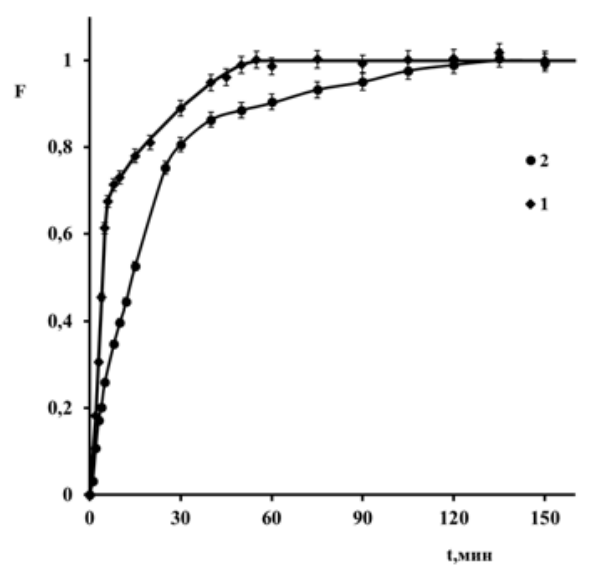

Рис. 5. Кинетические кривые сорбции ванилина анионообменником

Marathon MSA при различной исходной концентрации: $1-\mathrm{C}_{\text {исх }}=6$ ммоль/дм ${ }^{3}$, $2-\mathrm{C}_{\text {исх }}=1.7$ ммоль/дм ${ }^{3}$

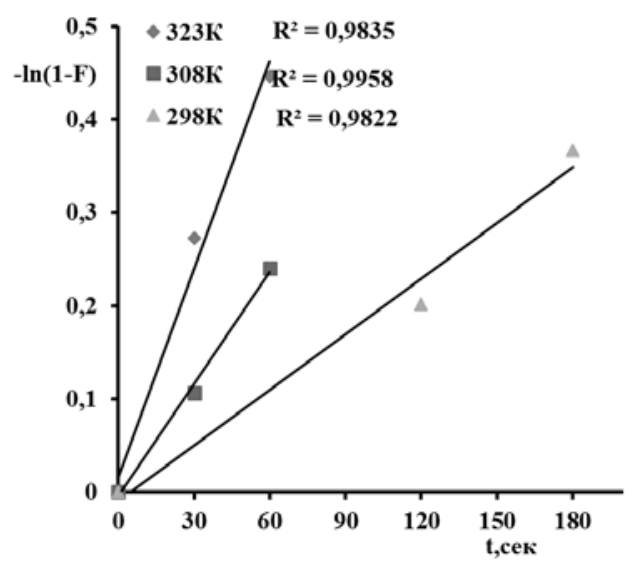

a

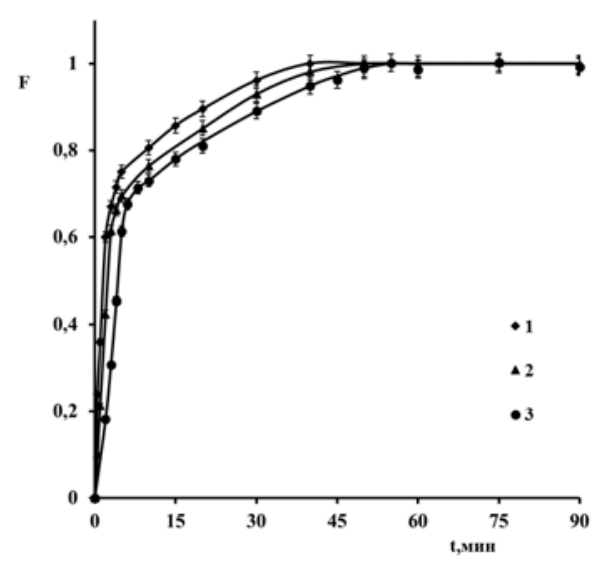

Рис. 6. Кинетические кривые сорбции ванилина анионообменником Marathon

MSA при различных температурах: $1-323 \mathrm{~K}, 2-308 \mathrm{~K}, 3-298 \mathrm{~K}$ $\left(\mathrm{C}_{\text {исх }}=6\right.$ ммоль/дм $\left.{ }^{3}\right)$

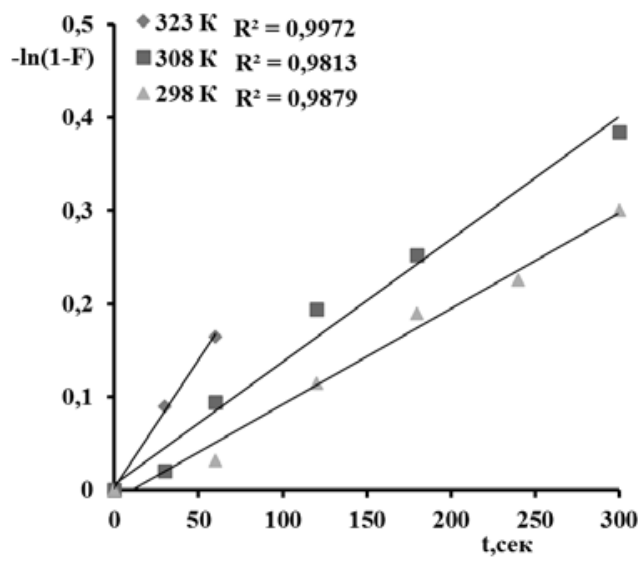

6

Рис. 7. Кинетические кривые сорбции ванилина анионообменником Marathon MSA из раствора с различной исходной концентрацией, построенные в координатах уравнения Бойда-Адамсона: а) $\mathrm{C}_{\text {исх }}=6.0$ ммоль/дм ${ }^{3}$, б) $\mathrm{C}_{\text {исх }}=1.7$ ммоль/дм ${ }^{3}$

Линейность зависимостей $-\ln \mathrm{F}=\mathrm{f}(\mathrm{t})$ на начальном этапе поглощения ванилина из растворов в исследуемом диапазоне концентраций характеризуется достаточно высокими коэффициентами корреляции, что позволяет сделать предположение о преобладании внешнедиффузионного механизма сорбционного процесса.

\section{Заключение}

В работе установлено, что сорбция ванилина макропористым сильноосновным анионообменником Marathon MSA в OH-форме имеет сложный полимолекулярный характер. Это связано с возможностью диссоциации молекулы ванилина в фазе сорбента с образованием ванилат-иона, который участвует в реакции анионного обмена с ОН-группами. Кроме того, в системе раствор альдегида - сорбент возможно дополнительное поглощение ванилина за счет различных более слабых взаимодействий. Методом ИК-спектроскопии подтверждено поглощение ванилина, а также наличие анионного обмена в системе. 
Исследование кинетических закономерностей процесса сорбции ванилина сильноосновным макропористым анионообменником показало, что в изучаемом диапазоне значений концентрации и температуры лимитирующей стадией сорбции является внешняя диффузия.

Результаты исследований получены на оборудовании ЦКП НО ВГУ

\section{Список литературы}

1. Тарабанько В.Е., Коропачинская Н.В. // Химия растительного сырья. 2003. № 1. С. 525

2. Першина Л.А., Ефанов М.В. // Химия растительного сырья. 1997. № 2. С. 42.

3. Zabkova M., Otero M., Minceva M. // Chemical Engineering and Processing. 2006. Vol. 45. pp. 598-607.

4. Андреева Л.Г., Романчук М.А., Зубакова Л.Б. и др. // Химико-фармачевтический журнал. 1972. №.7. С. 44-47.

5. Шолохова А.Ю., Воронюк И.В., Елисеева Т.В. // Сорбиионные и хроматографические проиессы. 2016. Т. 16. № 2. С. 220-225

6. Селеменев В.Ф., Славинская Г.В., Хохлов В.Ю. и др. Практикум по ионному обмену. Воронеж. Изд-во Воронеж. ун-та. 2004. $160 \mathrm{c}$.

7. Туторский И.А. Введение в коллоидную химию. Поверхностные явления и адсорбция

\section{References}

1. Taraban'ko V.E., Koropachinskaja N.V., Himija rastitel'nogo syr'ja, 2003, No 1, pp. 525.

2. Pershina L.A., Efanov M.V., Himija rastitel'nogo syr'ja, 1997, No 2, pp. 42.

3. Zabkova M., Otero M., Minceva M., Chemical Engineering and Processing, 2006, Vol. 45, pp. 598-607.

4. Andreeva L.G., Romanchuk M.A., Zubakova L.B. et al., Himiko-farmacevticheskij zhurnal, 1972, No 7, pp. 44-47.

5. Sholohova A.Yu., Voronyuk I.V., Eliseeva T.V., Sorbtsionnye i khromatograficheskie protsessy, 2016, Vol. 16, No 2, pp. 220-225.

6. Selemenev V.F., Slavinskaja G.V., Khokhlov V.Ju. et al., Praktikum po ionnomu obme$n u$, Voronezh, Izd-vo Voronezh. un-ta, 2004, $160 \mathrm{p}$.

7. Tutorskij I.A. Vvedenie v kolloidnuju himiju. Poverhnostnye javlenija i adsorbcija gaza газа на твердой поверхности. М. МИХТ им. М.В. Ломоносова. 2007. 87 с.

8. Фролов Ю.Г. Курс коллоидной химии. Поверхностные явления и дисперсные системы. Москва, Химия. 1988. 464 с.

9. Ebadi A, Mohammadzadeh Soltan J.S., Khudiev A. // Adsorption. 2009. No 15. pp. 6573.

10.Беллами Л. Инфракрасные спектры молекул. М. Изд-во иностранной литературы. $1957.444 \mathrm{c}$.

11.Преч Э. Определение строения органических соединений. М. Мир. БИНОМ. Лаборатория знаний. 2013. $439 \mathrm{c}$.

12.УГлянская В.А., Чикин Г.А., Селеменев В.Ф. и др. Инфракрасная спектроскопия ионообменных материалов. Воронеж. Изд-во Воронеж. ун-та. 1989. 205 с.

13.Boyd G.E., Adamson A.W., Myers L.S. // Contribution from the Glinton National laboratory. 1947. Vol. 69. pp. 2836-2838.

na tverdoj poverhnosti. Moskva, MIHT im. M.V. Lomonosova, 2007, 87 p.

8. Frolov yu.G. Kurs kolloidnoj himii. Poverhnostnye javlenija $i$ dispersnye sistemy. Moskva, Himija, 1988, 464 p.

9. Ebadi A, Mohammadzadeh Soltan J.S., Khudiev A., Adsorption, 2009, No 15, pp. 6573.

10.Bellami L. Infrakrasnye spektry molekul. M., Izd-vo inostrannoj literatury, 1957, $444 \mathrm{~s}$.

11.Prech Ye. Opredelenie stroenija organicheskih soedinenij. M., Mir, BINOM, Laboratorija znanij, 2013, 439 p.

12.Ugljanskaja V.A., Chikin G.A., Selemenev V.F. et al., Infrakrasnaja spektroskopija ionoobmennyh materialov. Voronezh, Izd-vo Voronezh. un-ta, 1989, $205 \mathrm{p}$.

13.Boyd G.E., Adamson A.W., Myers L.S., Contribution from the Glinton National laboratory, 1947, Vol. 69, pp. 2836-2838. 
Шолохова Анастасия Юрьевна - аспирант кафедры аналитической химии ФГБОУ ВО «Воронежский государственный университет», Воронеж

Елисеева Татьяна Викторовна - к.х.н., доцент кафедры аналитической химии ФГБОУ ВО «Воронежский государственный университет», Воронеж

Воронюк Ираида Владимировна - к.Х.Н., доцент кафедры аналитической химии ФГБОУ ВО «Воронежский государственный университет», Воронеж

Селеменев Владимир Федорович - д.Х.н., профессор, зав. каф. аналитической химии ФГБОУ ВО «Воронежский государственный университет» , Воронеж

Лукин Анатолий Николаевич - к.ф.-м.Н., доцент кафедры физики твердого тела и наноструктур ФГБОУ ВО «Воронежский государственный университет», Воронеж
Sholokhova Anastasiya Yu. - postgraduate student, Department of Analytical Chemistry, Voronezh State University, Voronezh, e-mail: shonastya@yandex.ru

Eliseeva Tatiana V. - lecturer, Department of Analytical Chemistry, Voronezh State University, Voronezh, e-mail: tatyanaeliseeva@yandex.ru

Voronuyk Iraida V. - lecturer, Department of Analytical Chemistry, Voronezh State University, Voronezh, e-mail i.voronyuk@yandex.ru

Selemenev Vladimir F. - professor, head of the department of Analytical Chemistry, Voronezh State University, Voronezh

Lukin Anatoly N. - Lecturer, Department of solid state physics and nanostructures, Voronezh State University, Voronezh 